\title{
O espetáculo da economia: a Primeira Exposição Nacional da Indústria no Império do Brasil, em 1861
}

Monica de Souza Nunes Martins ${ }^{1^{*}}$

${ }^{1}$ Universidade Federal Rural do Rio de Janeiro, Nova Iguaçu/RJ - Brasil

\section{RESUMO}

O artigo analisa a Primeira Exposição Nacional da Indústria, realizada no Brasil, em 1861, apoiada pelo governo imperial e organizada pela Sociedade Auxiliadora da Indústria Nacional e pelo Imperial Instituto Fluminense de Agricultura. O evento visava preparar a participação do Brasil na Exposição Universal em Londres, a se realizar em 1862. A partir de dados sobre investimentos do governo nesses eventos, objetivo compreender os impactos político e econômico que a Primeira Exposição representou para o país, considerando os produtos e os recursos naturais descritos no Relatório geral da Exposição Nacional de 1861 e no Relatório dos Jurys Especiais.

Palavras-chave: Exposição Nacional da Indústria; exposições universais; século XIX.

\section{The economic spectacle: the First National Industrial Exhibition during the Brazilian Empire, in 1861}

\section{ABSTRACT}

The article analyzes the first National Industrial Exposition in Brazil, which occurred in 1861 and was designed to prepare Brazilian industrialists for a global exposition in London the following year. The imperial government sponsored the event and the Sociedade Auxiliadora da Industria Nacional and the Imperial Instituto Fluminense de Agricultura organized it. This paper explores the political and economic impact of this first exhibition by

DOI: http://dx.doi.org/10.1590/2237-101X02104411

Artigo recebido em 10 de dezembro de 2018 e aceito para publicação em 2 de outubro de 2019.

* Professora da Universidade Federal Rural do Rio de Janeiro / Departamento de História, Nova Iguaçu/RJ - Brasil, pesquisadora associada ao INCT Proprietas/CNPq. Essa pesquisa foi parcialmente financiada pela Coordenação de Aperfeiçoamento de Pessoal de Nível Superior - Brasil (CAPES) - Código 001, Programa Professor Visitante Júnior no Exterior. E-mail: monicamartins@ufrrj.br. ORCID: https://orcid.org/00000003-0917-3437. 
examining data on government investment in the event and analyzing the natural products and resources described in the General Report of the National Exposition of 1861 and the Special Jurys Report.

Keywords: National Industry Exposition; Universal Exhibitions; nineteenth century.

\section{El espectáculo de la economía: la Primera Exposición Nacional de la Industria en el Imperio del Brasil, en 1861}

\section{RESUMEN}

El artículo analiza la Primera Exposición Nacional de la Industria, realizada en Brasil, en 1861, apoyada por el gobierno imperial y organizada por la Sociedad Auxiliadora de la Industria Nacional y por el Imperial Instituto Fluminense de Agricultura. El evento visaba preparar la participación de Brasil en la exposición universal en Londres, que se realizaría en 1862. A partir de los datos de inversiones del gobierno en estos eventos, pretendo comprender el impacto político y económico que la primera exposición representó para el país, considerando los productos y recursos naturales descritos en el Relatório Geral da Exposição Nacional de 1861y en Relatório dos Jurys Especiais.

Palabras clave: Exposición Nacional de la Industria; Exposiciones Universales; siglo XIX.

\section{Os espetáculos da indústria no Brasil}

A organização da Sociedade Auxiliadora da Indústria Nacional (SAIN) e do Imperial Instituto Fluminense de Agricultura (IIFA) imprimiu um aspecto singular nos procedimentos adotados pelo governo imperial brasileiro para apresentar o país nas exposiçôes universais da indústria do século XIX, a partir de 1862. A decisão de fazer parte desses espetáculos foi tomada com ressalvas. Em debates travados dentro da própria SAIN $^{1}$, a participação do Brasil era vista como oportuna e, ao mesmo tempo, causadora de incômodo. Os pontos centrais da contrariedade foram apresentados em debates diversos que sinalizavam a preocupação com a exibição da escravidão, as dificuldades em incorporar novas técnicas na produção agrícola e a falta de estrutura para impulsionar a produção fabril e o processo de industrialização no país.

\footnotetext{
${ }^{1}$ As questôes controversas se encontram nas páginas do Auxiliador da Indústria Nacional, disponível em: http://bndigital.bn.br/acervo-digital/auxiliador-industria-nacional/302295. Acesso em 15 nov. 2018.
} 
As grandes exposiçóes oitocentistas não eram homogêneas. Segundo Lúcia Guimarães, originaram-se de uma tradição francesa de promoção de feiras da indústria no país a cada cinco anos, desde 1798. No entanto, a exposição londrina de 1851 marcara a proeminência industrial, econômica e política mundial da Grã-Bretanha, já que esses eventos reuniam todos os campos da atividade agrícola, industrial e das belas-artes (GUIMARÁES, 2002, p. 252-253). As exposiçôes tornaram-se então o espelho das invençôes, das novidades na produção fabril e da consolidação da indústria como símbolo do progresso humano. Além disso, o espetáculo apresentado às naçôes era carregado de novos sentidos políticos que davam relevo aos países em franca industrializaçáo. ${ }^{2}$ Com efeito, segundo Silva (1992, p. 84), o significado social das feiras para a história comercial da Europa ao longo dos séculos se modificou essencialmente nos oitocentos, atendendo aos anseios e interesses da burguesia e distinguindo-se, náo apenas como espaço de vendas, mas como um potencial lugar de fomento a ideologias, ao conhecimento e de práticas diversas.

Desde a primeira iniciativa londrina de 1851 à explosão das que se seguiram na segunda metade do século XIX em vários países, houve, paralelamente, um significativo aumento do interesse e da presença efetiva de pessoas de diferentes origens sociais nos eventos. Tal intensidade, ${ }^{3}$ todavia, passou a representar as feiras também como um espaço crucial de concorrência, de negociaçóes comerciais, de divulgação das invençóes e de demonstração dos avanços tecnológicos dos países europeus e dos Estados Unidos, mas não apenas. A proliferação de novos produtos e a ampla participação de naçôes envolvidas, de expositores e de visitantes demonstram que, ao longo da segunda metade dos oitocentos, as feiras eram o mais significativo espaço de divulgação comercial de produtos diversos. A partir delas gerou-se um eixo de circulação de ideias e de técnicas (PLUM, 1979) que reforçavam o desenvolvimento acelerado da produção dos países do Atlântico Norte em contraposição à subordinação do restante do mundo. Ainda que diversos países estivessem presentes nas exposiçôes internacionais de aparente simetria, as desigualdades entre as várias partes do mundo também estavam ali expressas, mesmo que mitigadas pela ilusão de que as novidades do progresso e da modernidade se tornavam acessíveis a todos.

Entre os anos 1850 e o final do século esse crescimento das exposiçôes universais da indústria assumiu variados significados. A atração principal concentrada na indústria e nas invençôes tecnológicas, exibindo o passo à frente dado pelas naçôes do Atlântico Norte perante o mundo, não foi sempre a principal vitrine no decorrer do período, ao menos nos países fora do grande eixo de industrializaçấo. Nesse percurso, inicialmente a expansão da industrialização propiciava um campo de atençôes internacionais na disputada concorrência

\footnotetext{
${ }^{2}$ Importantes estudos sobre exposiçôes universais e seus impactos no Brasil oitocentista são PESAVENTO, 1997; KUHLMANN JR., 2001; NEVES, 1986. Para uma excelente análise da historiografia sobre as exposiçōes universais, cf. SANJAD, 2017.

${ }^{3} \mathrm{Na}$ exposição de 1851, em Londres, compareceram 6.039.150 visitantes e 13.937 expositores, ao passo que, na exposição parisiense de 1900, houve 32.250.297 visitantes e 61.722 expositores (PLUM, 1979).
} 
entre o que era produzido por cada nação, inclusive demonstrando as mudanças das bases produtivas mediante as inovaçôes tecnológicas. Conforme Rozendo Muniz, a ênfase genuína no inventário das forças produtivas dos países e das riquezas naturais era a base dos grandes eventos:

No apparato, nas galas e nos ornamentos deslumbrantes vae motivo secundário de honra e de fausto para a magestade da civilisação, cujo principal escopo nas exposições é inventariar as forças productivas naturaes e artificiaes de cada paiz $[. . .]^{4}$.

No Brasil, as consideraçóes feitas pelo Marquês de Abrantes, entáo presidente do conselho administrativo da SAIN, e por Militao de Villanova Machado, secretário-geral da SAIN, expressas em correspondência enviada ao Muniz da Silva Ferraz, ministro e secretário de Estado dos Negócios da Fazenda do império, publicadas no Auxiliador da Indústria Nacional, ${ }^{5}$ demonstram a mudança de sentido que as exposiçóes assumiram ao longo dos anos. Os missivistas avaliavam a pertinência, as vantagens e as desvantagens da participação do Brasil nas exposiçóes. Em suas percepçóes, retratavam a mudança de objetivos das grandes feiras que, de espaços de venda, converteram-se em locus de concorrência entre as naçôes. Com efeito, as feiras assumiram diferentes conotaçôes, atreladas cada vez mais aos interesses nacionais dos Estados em suas múltiplas açóes políticas, ideológicas, econômicas e diplomáticas (SILVA, 1992, p. 80). ${ }^{6}$

Isso nos leva ao segundo aspecto assumido pelas exposiçóes, o qual demostra forte assimetria, isto é, explicitavam-se as diversas áreas de expansão produtiva dos países e também das colônias, dando relevo ao potencial de cada uma delas no campo do desenvolvimento tecnológico, industrial, científico e na capacidade de fornecimento de matérias-primas. Não se tratava só de relação comercial, mas de um ambiente propício à visibilidade do poder de umas naçóes sobre outras, posto que as feiras visavam, na perspectiva dos países em processo de industrialização, caracterizar diferenças entre o "avanço" e o "atraso", a "civilizaçáo" e a "barbárie". Os recursos naturais, as commodities da produçáo capitalista, um dos nós da concorrência industrial na segunda metade do XIX, eram centrais na assimetria propositalmente narrada pelas naçóes imperialistas nos espaços de exibição (RYDELL; FINDLING; PELLE, 2000). O convite aos países periféricos não industrializados ou a inserção das colônias era fundamental para garantir a diversidade dessa "catalogação mundial" exposta, mapeando produtos diversos produzidos pela natureza ou pelo trabalho.

\footnotetext{
${ }^{4}$ MUNIZ, Rozendo. Exposição Nacional: notas e observaçôes. Rio de Janeiro: Typografia Nacional, 1876, p. 3-15.

${ }^{5}$ O Auxiliador da Indústria Nacional, $1^{\circ}$ de fevereiro de 1860, p. 73-77. Relatório dos trabalhos da SAIN durante o ano de 1859.

${ }^{6}$ Aqui Werneck da Silva analisa, em seu terceiro conjunto de hipóteses, as "razóes de Estado" presentes nas exposições, atendendo tanto às velhas nações como aos interesses das novas.
} 
Pelo exposto, um nó dessa análise são os múltiplos significados das exposiçôes, marcadas pela presença maciça de produtos diversos oriundos de florestas, reservas naturais e solos diferenciados pelo mundo afora. Encontrava-se nos estandes cada vez mais repletos de materiais os recursos naturais vindos de áreas periféricas de países industrializados, como os do Sul dos Estados Unidos, das colônias da África e da Ásia e dos países da América Latina. Nesse sentido, os recursos naturais foram centrais nas exibiçóes, constituindo-se em ponto de partida importante para a organizaçáo de eventos. Foi a partir daí que o Brasil se destacou em suas demonstraçóes de estímulo ao fomento da produção agrícola e de reserva de recursos naturais em catalogação.

Portanto, fundamental aqui é caracterizar o tipo de participação brasileira nas exposiçôes internacionais, nomeadamente calcada na abordagem da Primeira Exposição, em 1861, perscrutando os debates que a circundam, a presença austera da SAIN na organizaçáo e os interesses em jogo.

\section{A I Exposição Nacional e o empenho financeiro do governo}

O ingresso do Brasil nas exposiçóes universais a partir de 1862 deixa entrever a polêmica interna sobre o haver ou não vantagens da participaçáo brasileira. $\mathrm{O}$ forte investimento do governo imperial implicou incentivo político-administrativo e apoio logístico efetivo para a montagem da exposição. A inserção brasileira, no entanto, implicava esforços que abrangiam uma prévia avaliação dos produtos nacionais expostos nas províncias: seleção, exibição e premiação. Essas três etapas abarcavam, necessariamente, o envio dos produtos coletados por todas as províncias à corte do Rio de Janeiro, palco de exibição dos variados itens com potencial para a exibiçấo internacional. Ou seja, a organizaçấo de exposiçóes nacionais significava uma espécie de triagem de produtos, criaçóes artísticas ou invençôes a serem posteriormente expostas no exterior.

Logo de início, a própria catalogação era de caráter quase enciclopédico no sentido de registrar tudo o que fosse das ordens da natureza e da sociedade, pois era preciso bem exibir o país. Assim, a catalogação atendia a dois aspectos. Primeiro, tratava-se de um mapeamento geral das condiçôes sociais, administrativas, técnicas e produtivas do país que expressassem valorização dos elementos nacionais, ou seja, catalogar era também valorizar, enaltecer elementos e destacá-los em favor do próprio projeto imperial. Correspondiam àquela "homogeneizaçấo da visão de Brasil", da qual nos falava Guimarães (1988). Em segundo lugar, a catalogação tinha uma função política mais ampla, na medida em que informava aos países industrializados com interesse na exploração dos recursos naturais o que o Brasil tinha a oferecer.

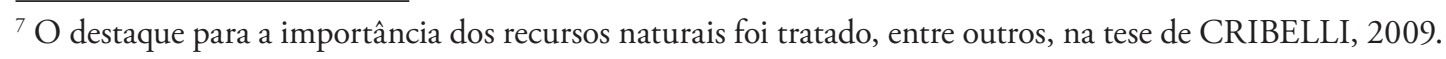


Ou seja, a vasta catalogação em relevo nas exposiçôes brasileiras fazia parte de um conjunto de interesses que, se atendiam à dinâmica imperialista, por outro lado também respondiam aos anseios dos setores agrícolas beneficiados internamente com essas açôes. Como se vê no Relatório geral da Exposição Nacional de 1861 e Relatório dos Jurys Especiais, expresso esse intuito: "Um dos beneficios que a actual Exposição pode fazer, é tornar conhecidos nos países industriosos um grande número de substâncias que o nosso atrasado estado de indústria não nos deixa aproveitar". ${ }^{8}$

Tomando como exemplo o catálogo da exposição do Brasil na Filadélfia, em 1876, já constituído de forma mais ampla que o da exposição de 1862, constata-se ser ele composto por 579 páginas distribuídas em várias seçōes. ${ }^{9}$ A abrangência dos aspectos elencados confirma a vasta expectativa em apresentar o que o Brasil podia oferecer em termos de produtos, mas também a forma como estavam dispostas as riquezas naturais em seu território.

Difícil pensar, no entanto, que tanto esforço e recursos, além dos infindáveis debates políticos sobre a presença do Brasil nesses eventos, tenha sido dispendido prioritariamente apenas pelo desejo do imperador em inserir o Brasil no âmbito das naçôes modernas e "civilizadas", trazendo ao país seu deslumbre com as recentes invenções. Toda essa mobilização para a organização das exposiçôes demandou uma aposta financeira alta do governo e de importantes instituiçóes do império comprometidos com todo o processo que envolvia a exposição dos produtos, desde a Exposição Nacional até a chegada deles ao exterior: transporte interno e externo, acondicionamento adequado, tratamento adequado das espécies por especialistas, montagem dos estandes no Brasil e no exterior, organizadores, comissões julgadoras, premiaçôes, produção de catálogos imensos etc. Todo esse empenho havia de trazer significativos ganhos, que se vinculavam sobretudo às esferas econômica e, como veremos adiante, diplomática, mas também contribuíam fortemente para o amálgama interno dos contornos nacionais que o império fomentava em prol da classe dominante.

Com esse intuito organizava-se a Primeira Exposição Nacional da Indústria, em dezembro de 1861, na corte do Rio de Janeiro, com a finalidade de selecionar os produtos a serem enviados à Exposição Universal de 1862, em Londres. Contando com mais de 50 mil visitantes, o primeiro evento organizado no Brasil surpreendeu pelo sucesso no número de expositores, de produtos e de visitantes. Então, foram publicados os Catalogos dos Produtos Naturaes e In-

\footnotetext{
${ }^{8}$ CUNHA, Antonio Luiz Fernandes da. Relatório geral da Exposição Nacional de 1861 e Relatório dos Jurys Especiais. Rio de Janeiro: Typografia do Diário do Rio de Janeiro, 1862, p. 30.

${ }^{9}$ O catálogo era dividido nas seguintes seçôes: Reino Animal, Reino Vegetal, Reino Mineral, Águas Mineraes, População, Constituição do Brazil, Divisão do Império, Força pública, Arsenaes de Guerra, Presídios e Colônias militares, Marinha Brazileira, Pharoes, Pharoletes, Cultural intelectual, Museus de História Natural, Bibliotecas, Imprensa, Associaçóes científicas, literárias e industriaes, Theatros, Docas, Pesos e medidas, Agricultura, Institutos Agrícolas, Indústria, Correio, Telégraphos elétricos, Vias de Comunicação, Immigração e Colonisação, Catechese, Estrangeiros, Naturalização, Fazenda Nacional, Dívida Pública, Systema monetário, Casa da Moeda, Commercio, Praças de Commercio, Instituiçóes Bancarias, Companhias Anônimas, Estabelecimentos de Caridade, Associaçôes Criativas e Beneficentes, Montes Pios, Casas de Correção, Iluminação Pública, Município da Capital do Império, Exposiçôes Industriaes, Commissão Directora da Exposição Nacional.
} 
dustriaes remettidos das provincias do Império do Brazil, com minuciosa descrição dos produtos da fauna, flora, recursos naturais e invençôes diversas enviadas por cada uma das províncias. ${ }^{10}$ Da mesma forma, incentivou-se as províncias a organizarem suas exposiçôes locais, criando-se para tanto as Instruç̧ôes para as Exposiçôes agrícolas nas Provincias do Império.

Essa primeira exposição foi realizada na Escola Central, no Largo de São Francisco, prédio adequado para a instalação dos estandes e exposiçấo dos produtos divididos em grupos: indústria agrícola, indústria fabril e manual, indústria metalúrgica, artes e produtos químicos, artigos manufaturados e belas artes.

Figura 1: Exposição Nacional

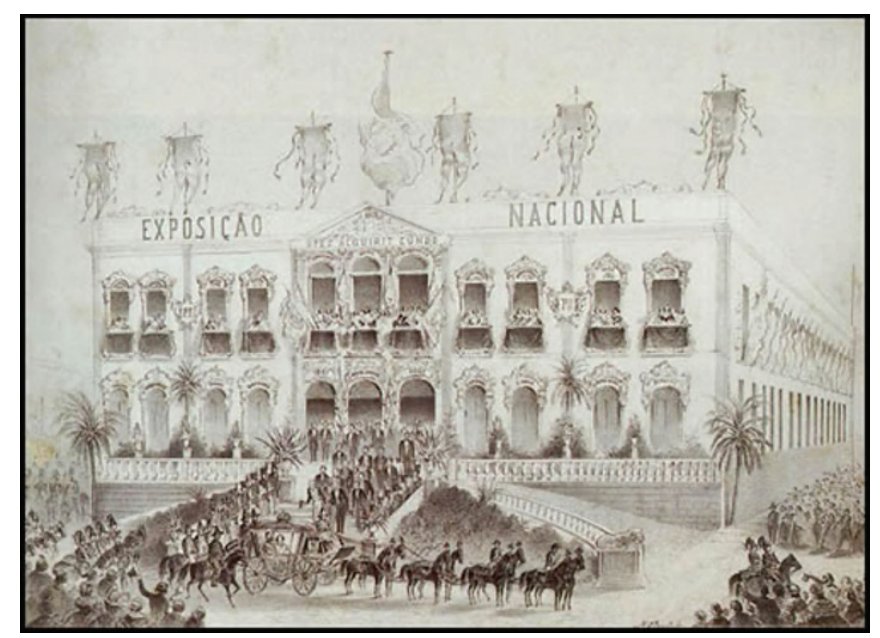

Fonte: Fleuiss. Exposição Nacional do Rio de Janeiro, 1861, litografia, Biblioteca Nacional.

Cabe sublinhar que esse evento esteve sob a alçada do Ministério do Comércio e Obras Públicas, criado em 1860, ao qual estavam ligados a Sociedade Auxiliadora da Indústria Nacional (SAIN) e o Imperial Instituto Fluminense de Agricultura (IIFA), instituiçóes que estiveram à frente dessa primeira e das exposiçóes seguintes. De cunho privado e financiadas pelos sócios, atuaram fortemente nas discussôes sobre produção industrial e agrícola no país, com papel destacado no empenho organizacional desses grandes eventos.

Em seguida, a chamada "febre de exposiçóes" se espalhou por várias províncias, algumas das quais organizaram exposiçôes regionais periodicamente, como aconteceu em outros países no período. Além disso, difundiram-se exposiçóes de caráter mais específico sobre determinados ramos do conhecimento, tais como exposição agrícola, exposição artística etc. $\mathrm{Ou}$ seja, disseminou-se certa cultura de exposiçôes que atingiria a elite intelectual oitocentista (GUIMARÃES, 2002, p. 253), associada a noções relacionadas à instrução. Eram exposi-

\footnotetext{
${ }^{10}$ Catálogo dos produtos naturaes e industriais remetidos das provincias do Império do Brazil. Rio de Janeiro: Typographia nacional, 1862. Cf. SANTOS; TORRES, 2012.
} 
çôes vistas como espaço de trocas de invençôes, de saberes e de informaçóes, com vistas ao implemento de condições para o progresso, ao mesmo tempo que pretendiam consolidar ali as condiçóes vitais para o estímulo ao desenvolvimento da indústria. Nesse ponto, é importante notar a força idealizadora e promotora das exposiçóes organizadas pela SAIN. ${ }^{11}$

$\mathrm{Na}$ introdução de Recordaçôes da Exposição Nacional de 1861, de caráter iconográfico, escrita pelo Marquês de Abrantes, descrevia-se que a Primeira Exposição Nacional fora mencionada por brasileiros e estrangeiros como "o primeiro e apressado inventário das forças produtivas no Brasil". ${ }^{12}$ Apesar disso, a exposição teve um sucesso de presença de expositores e visitantes e consagrou-se como um primeiro mapeamento geral dos recursos naturais e manufatureiros das diversas províncias, ainda que bem preliminar e incompleto, diante do que foi apresentado nas exposiçóes seguintes. Ainda segundo o Marquês, esse primeiro evento nacional produziu outros frutos de maior valia, quais sejam, a concorrência e a comparação de diversos produtos, na promoção do aprendizado mútuo entre todos os que expunham os defeitos e davam-se à oportunidade de aprender aperfeiçoamentos. ${ }^{13}$

A primeira exposição organizada na Corte envolveu um aparato significativo para receber produtos e visitantes, manter a exposição funcionando durante 16 dias e desempenhar a contento todo o procedimento de avaliação, seleçáo e premiação dos itens expostos. Para isso, o empenho em financiamento pago pelo Tesouro às províncias destinava-se em maior quantia àquelas que recolhiam produtos de regiôes vizinhas e as organizavam para o envio até a Corte, como foi o caso do Pará. Com participação das províncias, o evento se tornou maior do que previa a comissáo organizadora. Segundo o Relatório da Comissão, todo o edifício da Escola Central ficou lotado de produtos:

Suppoz-se no princípio que os objectos expostos mal occupariam algumas das salas do edificio da Escola Central, destinado para Palácio da Exposição Nacional; entretanto encheram-se todas as salas, vestibulos, galerias, páteos e terraços desse vasto edifício; que ficou de ta1 modo repleto que os objectos não puderam ser dispostos de um modo conveniente e methodico. ${ }^{14}$

O relato evidencia a forma confusa com que os produtos chegaram à Exposição Nacional, grande parte dos quais na véspera ou depois de já iniciado o evento; alguns, como os

\footnotetext{
${ }^{11}$ De acordo com Momesso: "No ano de 1824, quando não havia política orientada para a produção interna, Ignacio Alves Pinto, fabricante de aguardente, encaminhou a D. Pedro I os estatutos de uma sociedade que beneficiaria a 'indústria nacional', estabelecendo um depósito e conservatório de máquinas e moldes. O tribunal da Junta aprovou a existência da Sociedade Auxiliadora da Indústria Nacional, considerando que ela poderia ser de muita 'utilidade no adiantamento da agricultura e das artes'. O mesmo Ignacio Alves Pinto trabalharia sistematicamente para organizar a Exposição Nacional da Industria do ano de 1861” (2007, p. 44).

${ }^{12}$ Recordações da Exposição Nacional de 1861. Instituto Artístico de Fleiuss Irmãos \& Linde, Typographia Universal de Laemmert, 1862, p. 3. Rio de Janeiro, 1862. Disponível em: http://objdigital.bn.br/objdigital2/ acervo_digital/div_iconografia/icon493895/icon493895.pdf. Acesso em: 31 out. 2017.

${ }^{13}$ Idem.

${ }^{14}$ CUNHA, Antonio Luiz Fernandes da. Relatório geral da Exposição Nacional de 1861 e Relatório dos Jurys Especiais, op. cit., p. 12.
} 
da Província do Rio Grande do Sul, depois mesmo de terminada a feira. Por outro lado, as Exposiçôes Provinciais sugerem um empenho significativo na seleção e no envio dos produtos, apesar do pouco tempo e de dificuldades de transportes. O relatório descreve os esforços das exposiçóes e remessas de produtos do Pará, Amazonas e Pernambuco, que recebeu e reenviou itens de Alagoas, Rio Grande do Norte, Paraíba, Ceará e Piauí, províncias que apresentaram maior riqueza de produtos. Mais simples foram os catálogos remetidos por Minas, Paraná, Santa Catarina, Espírito Santo, Sergipe e Rio Grande do Sul. Mato Grosso e Goiás foram representados apenas por dois expositores de minerais, segundo o relatório. São Paulo e a Corte também expediram poucos produtos, de poucos expositores, segundo a descrição. Essas exposiçôes provinciais já eram um sucesso de participação de público, superando a expectativa dos organizadores. Somente a de Pernambuco, em sete dias, recebeu 12.357 pessoas. Esse interesse e receptividade para os eventos explicam o enorme êxito alcançado também pela Exposição Nacional na Corte e a afluência de visitantes de outras partes do império, como se vê no quadro 1 :

Quadro 1: Número de expositores

\begin{tabular}{|c|c|}
\hline Província & $\begin{array}{c}\text { Número de expositores na Exposiçáo } \\
\text { Nacional }\end{array}$ \\
\hline Corte e Província do Rio de Janeiro & 732 \\
\hline Pará & 76 \\
\hline Amazonas & 64 \\
\hline Bahia & 53 \\
\hline Minas Gerais & 45 \\
\hline Pernambuco & 44 \\
\hline Rio Grande do Sul & 42 \\
\hline Alagoas & 37 \\
\hline Ceará & 19 \\
\hline Paraná & 5 \\
\hline Sergipe & 3 \\
\hline Sáo Paulo & 4 \\
\hline Santa Catarina & 3 \\
\hline Rio Grande do Norte & 2 \\
\hline Piauy & 1 \\
\hline Espirito Santo & 1 \\
\hline Maranhão & 1 \\
\hline Mato Grosso & 1 \\
\hline Goyaz & 1 \\
\hline Parahyba & 1 \\
\hline
\end{tabular}

CUNHA, Antonio Luiz Fernandes da. Relatório geral da Exposição Nacional de 1861 e Relatório dos Jurys Especiais. Rio de Janeiro: Typografia do Diário do Rio de Janeiro, 1862, p. 20-21. 
Essa primeira iniciativa foi considerada muito exitosa, embora, se vista no cômputo geral das exposições nacionais realizadas no oitocentos, ela aparente pequenez, com um formato mais experimental. O relatório da exposição de 1875 se referiu à congênere de 1861 como portadora do "encanto da prioridade", 15 e até porque os catálogos posteriores eram mais precisos e completos. No entanto, na exposição de 1861 o império inaugurava seu repertório nacional e fomentava a grande amostra da produção brasileira.

Em relação aos produtos expostos os números são importantes. Ainda que muitos produtos de outras províncias tenham sido apresentados por expositores da Província do Rio de Janeiro, possivelmente pelas dificuldades de deslocamento, foi expressiva a quantidade de artigos diversos expostos pelas províncias (quadro 2).

Quadro 2: Produtos expostos

\begin{tabular}{|c|c|}
\hline Províncias & Produtos expostos \\
\hline Corte e Província do Rio de Janeiro & 5.928 \\
\hline Amazonas & 990 \\
\hline Pará & 924 \\
\hline Pernambuco & 470 \\
\hline Alagoas & 343 \\
\hline Rio Grande do Sul & 263 \\
\hline Minas & 187 \\
\hline Pará e Amazonas & 185 \\
\hline (Exposição do Barão de Mauá) & 151 \\
\hline Paraná & 107 \\
\hline Sergipe & 104 \\
\hline Bahia & 65 \\
\hline Espirito Santo & 59 \\
\hline Paraíba & 50 \\
\hline Rio Grande do Norte & 44 \\
\hline Santa Catarina & 36 \\
\hline Ceará & 35 \\
\hline Piauí & 16 \\
\hline São Paulo & 3 \\
\hline Maranhão & 1 \\
\hline Mato Grosso & 1 \\
\hline Goiás & \\
\hline
\end{tabular}

Fonte: CUNHA, Antonio Luiz Fernandes da. Relatório geral da Exposição Nacional de 1861 e Relatório dos Jurys Especiais. Rio de Janeiro: Typografia do Diário do Rio de Janeiro, 1862, p. 21-22.

O relatório sublinha as estatísticas da Exposição Nacional. Aberta entre 2 de dezembro de 1861 e 6 de janeiro de 1862, 42 dia de exposiçáo (excetuados três feriados), o total de

\footnotetext{
${ }^{15}$ MUNIZ, Rozendo. Exposição Nacional: notas e observações, op. cit., p. 189-194.
} 
visitantes atingiu 50.739 pessoas. Em seis dias em que a entrada foi gratuita houve 32.286 visitantes; em 29 dias nos quais se cobrou $1 \$$ pela entrada, 11.281 visitantes; e em sete dias a 500 rs, $7.172 .{ }^{16}$ Talvez este tenha sido o ponto mais surpreendente, pois a feira tinha potencial para atrair um grande público, muito além do previsto mesmo num país periférico sem investimento ou fomento à industrialização. Todos os recursos dotados pelo governo para transporte dos produtos das províncias para a Corte, acondicionamento dos produtos, montagem dos estandes, premiaçôes, transporte para a Inglaterra, tarifas e instalação da exposição brasileira em Londres, em 1862, significaram um total de gastos no valor de $77.084 \$ 420$.

Foram selecionados na Exposição Nacional e enviados para Londres 1.495 produtos, distribuídos em 39 grupos (quadro 3).

Quadro 3: Produtos selecionados para a Exposição Universal de 1862

\begin{tabular}{|c|c|}
\hline Produtos selecionados & Quantidade \\
\hline Amostras de madeiras & 318 \\
\hline Productos Chimicos e Pharmaceuticos & 225 \\
\hline Mineraes & 223 \\
\hline Substancias alimenticeas, inclusive vinhos & 162 \\
\hline Substancias animaes e vegetaes usadas nas fabricas & 153 \\
\hline Vidros e crystaes & 109 \\
\hline Photographias & 37 \\
\hline Amostras de algodão e seus tecidos & 22 \\
\hline Moedas & 20 \\
\hline Artes cerâmicas & 17 \\
\hline Tabaco em pó, rapé, charutos e cigarros (volumes) & 17 \\
\hline Artigos de vestuário & 16 \\
\hline Linho e matérias fibrosas & 14 \\
\hline Medalhas & 13 \\
\hline Couros e objetos de celeiros & 12 \\
\hline Ferro e ferragens e obras de ferro & 12 \\
\hline Cutelaria & 10 \\
\hline Sabão (volumes) & 10 \\
\hline Pinturas a óleo, aquarelas e desenhos & 10 \\
\hline Objectos de optica & 9 \\
\hline Machinas em geral & 8 \\
\hline Papel de forro (volumes) & 8 \\
\hline Diversos objetos & 8 \\
\hline Lá e seus tecidos & 7 \\
\hline
\end{tabular}

(cont.)

\footnotetext{
${ }^{16}$ CUNHA, Antonio Luiz Fernandes da. Relatório geral da Exposição Nacional de 1861 e Relatório dos Jurys Especiais, op.cit., p. 14-20.
} 
(cont.)

\begin{tabular}{|c|c|}
\hline Produtos selecionados & Quantidade \\
\hline Seda (Casulo, seda fiada, etc.) & 6 \\
\hline Tecidos e trançados de ouro, prata, etc. & 6 \\
\hline Marcenaria & 5 \\
\hline Pelles, pellos, cabelos & 4 \\
\hline Livros e amostras de encadernação & 4 \\
\hline Arquitectura naval e aparelho & 4 \\
\hline Objectos de sciencias naturaes & 4 \\
\hline Flores artificies (volumes) & 4 \\
\hline Objectos militares & 3 \\
\hline Ourivesaria & 3 \\
\hline Vellas de carnaúba, sebo e stearina (volume) & 3 \\
\hline Tinta de escrever (garrafas) & 3 \\
\hline Esculpturas & 3 \\
\hline Instrumentos d'agricultura & 2 \\
\hline Relojoaria & 1 \\
\hline
\end{tabular}

Fonte: CUNHA, Antonio Luiz Fernandes da. Relatório geral da Exposição Nacional de 1861 e Relatório dos Jurys Especiais. Rio de Janeiro: Typografia do Diário do Rio de Janeiro, 1862, p. 22-23.

Ao longo das décadas seguintes os gastos dispendidos nas exposiçóes tiveram expressivo aumento, indicando que, aos olhos dos organizadores, do governo e das instituiçóes promotoras, elas apresentariam satisfatório retorno. Era um alto investimento que deveria responder à altura das expectativas dos que investiam nos eventos. ${ }^{17}$

Villela Luz considerou as exposiçôes de 1861 e de 1866 realizadas no império como entusiastas da nascente indústria (LUZ, 1978, p. 45), ao mesmo tempo em que salienta o que ela denominou "indiferença" e "malevolência" de alguns em relação aos eventos. Esse entusiasmo remete exatamente ao forte empenho dispendido pelo governo para atender aos interesses diversos daquele momento, ainda que a maior contemplada tenha sido, sem dúvida, a própria indústria exportadora agrícola. Ao mesmo tempo o desdém foi aludido na documentação da SAIN, algumas vezes indicando a má vontade na participação de empresas e produtores ingleses radicados no Brasil para com as exposiçóes.

O valor dos gastos dispendidos pelo governo nessa Primeira Exposição Nacional e nas seguintes são caminhos para compreender, antes de tudo, a precisa avaliação coeva sobre os investimentos realizados nos eventos, o cálculo do alcance, os interesses a serem atingidos

\footnotetext{
${ }^{17}$ Outros dados em: Archivos da Exposição da Industria Nacional: actas, pareceres e decisóes do jury geral da exposiçáo da industria nacional realizada no Rio de Janeiro em 1881. Rio de Janeiro: Typografia Nacional, 1882. Biblioteca da Associação Industrial. Introdução de Antonio Augusto Fernandes Pinheiro. Essa fonte apresenta números diferentes para a presença nas exposiçóes. O total de visitantes seria de 18.453 pessoas. Mais precisos, os dados do Relatório são ricos em detalhes e constituem uma fonte importante com o resultado sobre o evento e com os valores financeiros arrecadados em relação ao número de presentes.
} 
e o retorno que o investimento traria para determinados setores da economia brasileira e para a própria política imperial. Apresentava-se como experiência inaugural da projeção das riquezas nacionais para o mundo, mas afirmava um lugar dentro do circuito comercial que se abria à circulação internacional de commodities.

O envio dos produtos nem sempre envolvia critérios tão óbvios de seleção e mesmo de reconhecimento sobre os benefícios de sua exposição, como foi o caso de substâncias de caráter medicinal enviadas à corte sem o devido aval de médicos. O catálogo de 1862 chega a mencionar que um grande número delas foi submetido à exposição da Corte, mas "[...] sendo este um assunto muito delicado e sobre o qual só se deve falar depois de experiências feitas com o devido critério por médicos reconhecidos experimentadores, a Comissão abstem-se de emitir sua opinião [...]". ${ }^{18}$ Tratava-se, em quantidade, do segundo produto a ser exposto pelo Brasil em Londres.

A seleçấo abrangia amostras de muitos e diversificados itens da flora e fauna, muitos que necessitavam de acondicionamento adequado, além de sua eficácia aprovada e reconhecida por pares profissionais, como o caso de produtos de uso medicinal. Esse era o aspecto que envolvia também a credibilidade sobre aquilo que era apresentado como resultado do trabalho, elemento fundamental para caracterizar o que podia se destacar como objeto de exposição. Além do resultado do trabalho, o item deveria ser reconhecido no meio científico ou com valor de mercado.

O envolvimento pessoal do imperador com a exposição foi notório ${ }^{19}$. Para o desenlace do evento ele próprio recomendou às províncias que enviassem para a Corte "os objectos capazes de dar ideia dos differentes ramos de industria das respectivas províncias" 20 , o que atesta sua pressão direta sobre os presidentes de províncias para a participação nas feiras. Isso, de certa forma, explica muito dos números relacionados a essa grande participaçáo de expositores e produtos no primeiro evento, apesar das dúvidas, incertezas e desconfianças de proprietários diversos e sobre a recepção do público. De acordo com Freitas Filho (1991), as exposições nacionais, na definição de Frederico Leopoldo César Burlamaque, secretário perpétuo da SAIN, e também secretário da comissão organizadora da I Exposição Nacional de 1861, não se constituíam em "meros espetáculos de curiosidade, mas sim um grande ensino para a agricultura, a indústria, o comércio e as artes [...] um inquérito palpável, um inventário da riqueza pública, um grande passo na via do aperfeiçoamento e do progresso". ${ }^{21}$

${ }^{18}$ Catálogo dos produtos naturaes e industriais remetidos das províncias do Império do Brazil. Rio de Janeiro: Typographia Nacional, 1862.

${ }^{19}$ Sobre o perfil político e intelectual do imperador, ver CARVALHO, 2007.

${ }^{20}$ Catálogo dos produtos naturaes e industriais remetidos das provincias do Império do Brazil. Rio de Janeiro: Typographia Nacional, 1862, p. 8.

${ }^{21}$ Exposiçấo Nacional de 1861. Documentos officiaes relativos à Exposição Nacional de 1861 [...]. Rio de Janeiro: Typografia do Diário do Rio de Janeiro, 1862. 
Nesse esforço, o governo publicou também as "Instruçôes para as Exposiçôes Agrícolas nas Províncias do Império", que, em 22 artigos, indicava como os eventos nas províncias deveriam ser organizados. Nas instruçôes, algumas províncias foram designadas para abrigar as exposiçôes regionais, recebendo de regiôes mais próximas produtos comercializáveis, fabris ou técnicos. Pará, Pernambuco, Bahia, Minas Gerais e São Pedro foram as capitais escolhidas para abrigar as amostras. As províncias do Nordeste apresentaram maior variedade de produtos se comparadas a São Paulo e ao Centro Sul.

$\mathrm{Na}$ I Exposição priorizou-se apresentar instrumentos de beneficiamento de produtos agrícolas, indicados no Catálogo dos produtos naturais e industriais que figuram na exposição nacional de 1861. ${ }^{22}$ Talvez a importância das feiras nacionais e dos melhoramentos propostos contribua ao entendimento de tanto deslocamento de visitantes para os eventos num país de dimensôes continentais. Alguns beneficiamentos estavam adequados, por exemplo, ao que era útil para agricultores e produtores no Brasil, menos preocupados com inventos que agradassem aos olhos estrangeiros e mais atentos aos benefícios cotidianos da produção agrícola. Interessante também observar que o júri da exposição indicou quais seriam as invençóes e necessidades mais urgentes para a lavoura do país, indicando a utilização das máquinas como "um processo auxiliar na substituição da mão-de-obra escrava que escasseava". 23

As mudanças suscitadas nos objetivos traçados pelas exposiçóes nacionais também revelam preocupação com aspectos que envolviam a vida de trabalhadores: a disciplina do trabalho, a higiene, a moral e os vícios; tudo isso era tema de divulgação e consumo. No Brasil o periódico publicado pela SAIN, O Auxiliador da Indústria Nacional24, relacionou a economia doméstica nas exposiçôes universais com publicaçôes de caráter didático para os trabalhadores.

Aliás, segundo Murasse, esse foi o propósito do Auxiliador da Indústria Nacional, o caráter educativo associado à difusão de conhecimento útil aos "homens industriosos". Assim, os artigos do periódico se dedicaram a tratar de temas caros em publicaçóes similares em outros países cujos interesses já versavam nos estandes das exposiçôes internacionais, tais como conhecimento associado à agricultura, economia doméstica, artes, medicina prática, economia rural e industrial etc. (MURASSE, 2006). O relato das recordaçôes da I Exposição aludem enfaticamente a esse intuito instrutivo das feiras ao dar destaque ao caráter de ensino mútuo presente nos eventos, na medida em que eram divulgados beneficiamentos que concorreriam para a melhoria geral dos processos inventivos e produtivos no país, nos quais a concorrência também era vista positivamente para esse estímulo. ${ }^{25}$

${ }^{22}$ Catálogos dos Produtos Naturaes e Industriais Remettidos das Provincias do Império do Brasil, Typographia Nacional: Rio de Janeiro, 1861.

${ }^{23}$ Idem.

${ }^{24} \mathrm{O}$ Auxiliador da Indústria Nacional circulou entre 1833 e 1892, tendo produzido 720 números. Periódico mensal, era editado pela Sociedade Auxiliadora da Indústria Nacional. Com a queda da monarquia, sua tiragem tornou-se irregular e ele parou de circular em 1903. Ver COSTA, 2012, p. 151-155.

${ }^{25}$ Recordaçôes da Exposição Nacional de 1861, op. cit., p. 6. 
Esse propósito pedagógico marcou um ideal da SAIN de se consolidar como referência e porta-voz desse universo ligado a vários setores produtivos no Brasil, pelo menos até os anos 1880, o que nos remete ao entendimento do próprio significado de indústria no século XIX. Esse tema, já tão bem analisado na historiografia (BEAUCLAIR, 1992; SILVA, 1979), redimensiona o termo indústria no período, que não se confunde com os sentidos modernos. Tratava-se de pensar de forma mais ampla as esferas produtivas da economia como um todo. Os próprios estatutos da SAIN já mencionavam essa ampla conotação, e, embora reconhecessem a aplicação específica à produção manufatureira, destacavam a indústria como síntese do tripé da produçáo agrícola, artesanal e comercial. Assim, apenas mais tarde o termo indústria foi especificamente associado à esfera fabril; no século XIX à indústria estavam ligadas todas as acepçôes de invenção, criação e produção, especialmente quando a estes se atribuía um valor econômico associado. E esse sentido amplo nos ajuda a entender a própria composição diversificada SAIN, que abrigava quadros pertencentes a vários âmbitos da produção nacional, agricultores, fabricantes, artistas, comerciantes, "ou seja, todos aqueles capazes de prover a indústria” (SILVA, 1979, p. 95).

\section{Impacto político e econômico das exposições para o Brasil}

De fato, é fundamental analisar as exposiçôes no seio das transformaçôes do capitalismo liberal concorrencial para o capitalismo financeiro (SILVA, 1992, p. 40), entendendo esses eventos no processo de afirmaçáo dos vários setores da burguesia e de seus projetos políticos e econômicos. Nesse sentido, se por um lado esses eventos exaltavam o progresso, também eram carregados de silenciamento a respeito de todo problema social que se opunha à imagem do progresso, da modernidade e da ideia ufanista do processo de industrialização. Foram terrenos férteis, portanto, para serem semeadas as ideologias do século XIX que embasaram tanto a consolidaçáo capitalista quanto um projeto de ideal burguês, vinculados a uma noçáo de desenvolvimento articulada ao processo de desenvolvimento tecnológico.

Dentro dessa perspectiva mais ampla, as naçóes periféricas e as regióes coloniais inseriam-se como peças da engrenagem econômica de sustentaçáo ao capitalismo, mas que em grande medida a elas também interessava. Representavam, em diferentes escalas, a expressão do atraso em relação às naçóes industrializadas e, por outro lado, eram incorporadas às feiras numa aparente simetria na qual todas elas poderiam fazer parte das mesmas festas, para a qual eram convidadas e optavam por participar. No caso do Brasil esse lugar foi peculiarmente composto. Sua posição estratégica na América Latina, a partir de suas dimensôes continentais e fronteiras com diversos países, atraía os interesses político-estratégicos dos 
países centrais ${ }^{26}$, ao mesmo tempo que internamente se costuravam os acordos que levavam o país a expor sua produção e suas riquezas naturais ao mundo.

Todavia, na perspectiva do governo imperial, as exposiçôes também serviram a arranjos políticos internos no momento de consolidação do poder saquarema numa conjuntura importante para a composição de um projeto nacional imperial (MATTOS, 1987). Nos anos 1850 foram feitas mudanças legislativas profundas determinando um novo rumo para as decisóes políticas e econômicas do império, sobretudo no tocante ao comércio de escravos, à política de terras e às práticas comerciais. A participação do país nas exposiçôes portava a dupla tarefa de, por um lado, identificar as múltiplas características da produção da riqueza nacional, e, de outro, expor o que mais diretamente fazia parte da pauta econômica dos interesses externos diplomáticos. Nessa segunda direção, houve aprofundamento das relaçóes diplomáticas com os demais países, algo bem retratado nas exposiçôes das décadas seguintes, sobretudo na exposição comemorativa do centenário da Independência dos Estados Unidos de 1876, na Filadélfia, onde o próprio imperador do Brasil se fez presente. ${ }^{27}$

Essa tomada de posição do Brasil fazia parte de uma agenda econômica diversificada. O crescimento das exportaçóes brasileiras de café, açúcar e algodáo, bem como o investimento no comércio de matérias-primas desejáveis a indústrias recém-instaladas na Europa e Estados Unidos, produziu um ambiente favorável à apresentação do Brasil perante o mundo no século XIX. Sob a pressão de produtores diversos e pauta antiga da própria SAIN, a monarquia se convenceu disso e decidiu impulsionar o Brasil a participar das grandes exposiçóes. Seria um estímulo para espetacularização da nação, tornando seus símbolos nacionais também objetos de atração aos olhares internacionais. Movimentava-se externamente no sentido dos interesses dos setores agricultores dos exportadores de matérias-primas, que, amparados pela voz da SAIN, viam-se bem representados em seus interesses. Como salientou Villela Luz, o Brasil que vai às exposiçôes é claramente agrário e agroexportador (LUZ, 1978, p. 80).

Ao que tudo indica, as exposiçóes nacionais serviam ainda para a divulgação interna dos produtos nas relaçóes comerciais entre as províncias. Há de se notar que havia uma ampla rede de circulação comercial no Brasil desde o período colonial e que foi fundamental também para a economia imperial. Marcondes (2012) analisou como o comércio de cabotagem propiciou intensas trocas entre as províncias, possibilitando o crescimento comercial de cada uma delas na importaçáo de gêneros nacionais e de sua enorme variedade, especialmente as províncias do Rio Grande do Sul, Rio de Janeiro, Pernambuco e Pará entre os anos de 1839 e 1873. Assim, houve expressivo crescimento após os anos 1850 de

\footnotetext{
${ }^{26}$ Heizer chama atenção para a singularidade dos projetos dos países da América Latina, que buscavam distinguir-se no contexto internacional ao se apresentarem. Nesse intuito, por exemplo, Brasil e Argentina expunham ao mundo o que queriam dizer de si mesmos. Ver HEIZER, 2010, p. 1-16

${ }^{27}$ Sobre a presença do imperador nessa exposição e seu significado para o Brasil, ver SCHWARCZ, 1998, p. 385-407; PESAVENTO, 1994; CRIBELLI, 2009, p. 223-254; MACHADO, 2017.
} 
produtos comercializados por cabotagem, com destaque para o açúcar (16\%), o algodão $(14,1 \%)$ e o café $(14 \%)$, entre $1869-1873 .{ }^{28}$

Além do aumento da circulação de gêneros nacionais de produtos entre as províncias, após os anos 1860 os pareceres feitos pela SAIN ao Ministério da Agricultura, Comércio e Obras Públicas demonstram cada vez de forma mais detalhada a descrição da produção realizada pelo país em vários setores, os pedidos de fundação de fábricas, os pedidos de privilégios industriais e de patentes (SILVA, 1979, p. 105-110). Desde 1857 fora previsto na reforma dos estatutos da SAIN a organização de exposiçôes nacionais a fim de promover o melhoramento e a prosperidade de todos os ramos da indústria. Portanto, mesmo diante dos debates suscitados sobre a participação ou não do país nas exposiçôes (MARTINS, 2017) - especialmente quando o mundo visse a escravidão -, elas já eram previstas como meio de divulgação e promoção das atividades produtivas nacionais.

Mas é de se notar o impacto dessas exposiçôes sob a ótica da SAIN. Instituição fundamental na formação do império brasileiro, ela desempenhou especial influência sobre a formação de outras duas instituiçôes: o Instituto Histórico e Geográfico Brasileiro, fundado em 1838 (GUIMARÁES, 1988, p. 7-8), e o Imperial Instituto Fluminense de Agricultura, fundado em 1860 (MARTINS, 1995). Os próprios membros da SAIN, por sua vez, eram os integrantes do quadro administrativo e diretor da IIFA, tendo sido esta fruto de um antigo sonho largamente difundido pelo Auxiliador da Indístria Nacional desde sua fundação: a formação de uma instituição agrícola. Isto remente a um ponto importante, qual seja, as relaçóes imbricadas entre agricultura e a chamada "indústria" nesse momento. Um setor industrial cujos interesses se definiam em articulação estreita com os interesses agrários, especialmente preocupados na questão da propriedade - em foco, a propriedade escrava - e com as políticas do governo concernentes à exportação. Por outro lado, havia um elemento-chave que fundamenta princípios para essas instituiçôes: atuar na consolidação de uma visão de Brasil pela construçáo de uma totalidade denominada identidade nacional (GUIMARÃES, 1988, p. 8).

A própria SAIN fez uma avaliação não muito otimista sobre a Primeira Exposiçãa. Apesar de reconhecer o potencial das províncias e atestar o que o Brasil estava em condiçóes de apresentar no exterior, reconhecia a necessidade de melhoramentos na indústria fabril. Esse entrave aos melhoramentos, no entanto, foram atribuídos ou a uma falta de instrução daqueles responsáveis pela condução das atividades rurais e mecânicas ou ao costume arraigado de fazer uso de técnicas já acomodadas, sem dar-se ao trabalho de investir em melhorias. ${ }^{29}$ Nota-se que em nenhum momento a SAIN menciona a condução do governo nesse processo, posto que a responsabilidade era atribuída aos indivíduos, às suas aptidóes, vontades e

\footnotetext{
${ }^{28}$ Há uma importante bibliografia sobre o comércio e abastecimento interno no Brasil no século XIX, para a qual citamos algumas referências: MARTINS, 1980; LINHARES; SILVA, 1981; FRAGOSO, 1992; LENHARO, 1993; FRAGOSO; FLORENTINO, 1993.

${ }^{29}$ O Auxiliador da Indústria Nacional, 1862, p. 90.
} 
esforços, mas no decorrer da avaliação sobre a exposição ela faz uma discreta provocação, salientando que não cabia a ela indicar quais seriam os melhoramentos, mas "conforta-nos a esperança de que não terá escapado esse estudo às magnânimas vistas do governo imperial". ${ }^{30}$

\section{Conclusão}

Enquanto "santuários das mercadorias" (SILVA, 1992, p. 39) as exposições universais marcaram a entrada do Brasil num novo circuito de exibição da sua produção e dos recursos naturais ao resto do mundo. Se os catálogos, traduzidos inclusive em outras línguas, apresentaram as riquezas naturais do país, também serviram para uma exibição interna ou uma espécie de autoconhecimento da indústria. No entanto, podemos pensar essas exposiçóes muito além do lugar de espaços de exibição de produtos, mas como um triunfante vendedor e disseminador de ideias políticas no século XIX.

A decisão de participar dessas exposiçóes demonstra também o quanto o governo exercia uma função importante na decisão sobre a participação e o quanto atendia a interesses de setores da economia na exibição nesses eventos. Ressalta-se ainda que não era o Brasil como um todo que participava dos eventos, nele estavam inseridos os ramos da produçáo e das riquezas naturais que se pretendia de fato apresentar ao exterior. Com o passar dos anos também aumentaria a concorrência entre as províncias nas exibiçôes nacionais e internacionais, demonstrada pela extensão, localização e arquitetura dos estandes e pavilhôes, bem como pela quantidade de produtos expostos.

Pelo Auxiliador da Indústria Nacional é notório como esse esforço foi um passo importante para as avaliaçóes da SAIN sobre vários aspectos relacionados à produção no país, a partir da qual se podiam identificar os limites, a necessidade de estímulos, os setores vocacionais que o Brasil deveria investir etc. Há de se destacar, no entanto, que essas possibilidades abertas pela catalogação e pela exibição, pelo envolvimento de diferentes províncias e produtores nas exposiçóes, todo esse aparato esteve voltado aos interesses mais diretamente ligados a setores muito restritos da produção nacional; produção circunscrita ao estímulo a determinados setores da agricultura e profundamente ligada aos interesses externos, o que se evidencia na priorização de importações de recursos e produtos que poderiam ser fomentados internamente. Essa voz das exposiçóes não falava apenas da capacidade produtora do Brasil, mas também do país que optava por se posicionar na esfera de dependência dos países industrializados.

\footnotetext{
${ }^{30} \mathrm{Idem}$.
} 


\section{Fontes primárias}

CUNHA, Antonio Luiz Fernandes da. Relatório geral da Exposição Nacional de 1861 e Relatório dos Jurys Especiais. Rio de Janeiro: Typografia do Diário do Rio de Janeiro, 1862. Catálogos dos Produtos Naturaes e Industriais Remettidos das Provincias do Império do Brasil, Typographia Nacional: Rio de Janeiro, 1861.

Exposição Nacional de 1861. Documentos officiaes relativos à Exposição Nacional de 1861. Rio de Janeiro: Typografia do Diário do Rio de Janeiro, 1862.

MUNIZ, Rozendo. Exposição Nacional: notas e observaçóes. Rio de Janeiro: Typografia Nacional, 1876.

O Auxiliador da Indústria Nacional. Disponível em: http://bndigital.bn.br/acervo-digital/ auxiliador-industria-nacional/302295. Acesso em: 15 nov. 2018.

Recordaçóes da Exposição Nacional de 1861. Instituto Artístico de Fleiuss Irmãos \& Linde, Typographia Universal de Laemmert, Rio de Janeiro, 1862. Disponível em: http://objdigital. bn.br/objdigital2/acervo_digital/div_iconografia/icon493895/icon493895.pdf. Acesso em: 31 out. 2017.

Revista Semana Ilustrada, ano 1, n. 15, p. 8, 24 mar. 1861.

\section{Referências}

BEAUCLAIR, Geraldo. Raizes da indústria no Brasil. Rio de Janeiro: Studio F\&S Editora, 1992.

CARVAlHO, José Murilo de. D. Pedro II. São Paulo: Companhia das Letras, 2007.

COSTA, Carlos. A revista no Brasil do século XIX. A história da formação das publicaçóes, do leitor e da identidade nacional do brasileiro. São Paulo: Alameda, 2012.

CRIBELLI, Teresa. Aperfeiçoar or Criar: dilemmas of Brazilian modernization, 1850-1889. PhD. Philosophy. The Johns Hopkins University, Maryland, 2009.

CRIBELLI, Teresa. A Modern Monarch: Dom Pedro II's visit to the United States in 1876. The Journal of the Historical Society, IX, p. 223-254, 2009.

FILHO, Almir Pitta Freitas. Tecnologia e escravidão no Brasil: aspectos da modernização agrícola nas exposiçóes nacionais da segunda metade do século XIX (1861-1881). Revista Brasileira de História, São Paulo, v. 11, n. 22, p. 71-92, mar./ago. 1991.

FRAGOSO, João. Homens de grossa aventura: acumulação e hierarquia na Praça Mercantil do Rio de Janeiro, 1790-1830. Rio de Janeiro: Arquivo Nacional, 1992. 
FRAGOSO, João Luís Ribeiro; FLORENTINO, Manolo. O arcaísmo como projeto: mercado atlântico, sociedade agrária e elite mercantil no Rio de Janeiro, c. 1790-c. 1840. Rio de Janeiro: Civilização Brasileira, 1993.

GUIMARÃES, Lúcia. Exposições. In: VAINFAS, Ronaldo. (dir.). Dicionário do Brasil Imperial (1822-1889). Rio de Janeiro: Objetiva, 2002. p. 252-253.

GUIMARÃES, Manoel Salgado. Nação e civilização nos trópicos: o Instituto Histórico Geográfico Brasileiro e o projeto de uma história nacional. Estudos Históricos, Rio de Janeiro, n. 1 , p. 5-27, 1988.

HEIZER, Alda. Consideraçóes sobre a participação da América Latina nas grandes exposiçóes da segunda metade do século XIX. Revista Eletrônica da ANPHLAC, n. 9, p. 1-16, 2010.

KUHLMANN Jr., Moysés. As grandes festas didáticas: a educação brasileira e as exposiçôes internacionais, 1862-1922. São Paulo: Universidade de São Francisco, 2001.

LENHARO, Alcir. As tropas da moderação: o abastecimento da Corte na formação política do Brasil, 1808-1842. 2. ed. Rio de Janeiro: Secretaria Municipal de Cultura, Turismo e Esportes, DGDIC, Divisão de Editoração, 1993.

LINHARES, Maria Yedda; SILVA, Francisco Carlos Teixeira da. História da agricultura brasileira: combates e controvérsias. São Paulo: Brasiliense, 1981.

LUZ, Nícia Vilela. A luta pela industrialização no Brasil. São Paulo: Editora Alfa-Ômega, 1978.

MACHADO, Marina; MARTINS, Mônica. A modernidade nas teias da floresta: o Brasil na Exposição Universal da Filadélfia, de 1876. Geosul, n. 65, jul.-dez. 2017.

MARCONDES, Renato Leite. O mercado brasileiro do século XIX: uma visão por meio do comércio de cabotagem. Revista de Economia Política, v. 32, n. 1 (126), p. 142-166, São Paulo, jan./mar. 2012.

MARTINS, Maria Fernanda Vieira. O Imperial Instituto Fluminense de Agricultura: elites, política e reforma agrícola (1860-1897). Dissertação (Mestrado em História). Niterói: UFF, 1995.

MARTINS, Roberto. A economia escravista de Minas Gerais do século XIX. Belo Horizonte, CEDEPLAR/UFMG, 1980.

MATTOS, Ilmar Rohloff de. O Tempo Saquarema. São Paulo: Hucitec, 1987.

MOMESSO, Beatriz Piva. Indístria e trabalho no século XIX: o estabelecimento de fundaçáo e máquinas de Ponta d'Areia. Dissertação (Mestrado em História). Programa de PósGraduação em História, Universidade Federal Fluminense, 2007.

MURASSE, Celina. O jornal O Auxiliador da Indústria Nacional e a campanha pela fundação de instituiçôes educativas: 1833 a 1850. In: Anais do Congresso Brasileiro de História da Educação, 4, 2006, Goiânia, GO. Goiânia: CBHE, 2006. Disponível em: http://www. 
sbhe.org.br/novo/congressos/cbhe5/pdf/39.pdf. Acesso em 15 nov. 2018.

NEVES, Margarida de Souza. As vitrines do progresso. Rio de Janeiro: Finep, 1986.

PESAVENTO, Sandra. Exposiçôes universais: espetáculos de modernidade no século XIX. Sáo Paulo: editora Hucitec, 1997.

PESAVENTO, Sandra. Imagens da nação, do progresso e da tecnologia: a Exposição Universal da Filadélfia de 1876. Anais do Museu Paulista, v. 2, n. 1, São Paulo, 1994.

PLUM, Werner. Exposiçóes no século XIX: espetáculos da transformação sociocultural. Bonn: Friedrich-Ebert-Stiftung, 1979.

RYDELL, Robert; FINDLING, John; PELLE, Kimberly. Fair America: world's fairs in the United States. Washington and New York: Smithsonian Books, 2000.

SANJAD, Nelson. Exposiçôes internacionais: uma abordagem historiográfica a partir da América Latina. História e Ciências Saúde-Manguinhos, v. 24, n. 3, jul./set. 2017.

SANTOS, Araci Alves; TORRES, José Celso. O catálogo de produtos naturais e industriais da Primeira Exposição Nacional. Anais do 130 Seminário Nacional de História da Ciência e da Tecnologia, Universidade de São Paulo (USP), set. 2012. Disponível em: https://www.13snhct.sbhc.org.br/resources/anais/10/1345058460_ARQUIVO_ TrabalhoCatalogo-JoseCelsoTorres.pdf. Acesso em: 12 dez. 2018.

SCHWARCZ, Lilia Moritz. As barbas do imperador: D. Pedro II - um monarca nos trópicos. São Paulo: Companhia das Letras, 1998. p. 385-407.

SILVA, José Luiz Werneck da. As arenas pacificas do progresso. As exposiçöes internacionais do século XIX. Tese (Doutorado em História), Programa de Pós-Graduação em História, Universidade Federal Fluminense, 1992.

SILVA, José Luiz Werneck da. Isto é o que me parece: a Sociedade Auxiliadora da Indústria Nacional (1827-1904) na formação social brasileira. A conjuntura de 1871 até $1877.2 \mathrm{v}$. Dissertação (Mestrado em História), Programa de Pós-Graduação em História, Universidade Federal Fluminense, 1979. 